\title{
Evaluation of the Sensitivity of Staphylococcus aureus Isolated from Nasal Swabs to Natural Honey
}

\section{A Molanaei ${ }^{1}$, SA Seyedoshohadaei ${ }^{2}$, S Hasani ${ }^{3}$, P Sharifi ${ }^{4}$, M Rashidian ${ }^{5}$, A Taherpour ${ }^{5}$, S TozandehJani ${ }^{6}$, S Hasani ${ }^{*}$}

1. Department of Internal Medicine, Kurdistan University of Medical Sciences, Sanandaj, Iran

2. Department of Psychiatry, Kurdistan University of Medical Sciences, Sanandaj, Iran

3. Department of Microbiology Sciences, Islamic Azad University, Sanandaj Branch, Sanandaj, Iran

4. Department of Microbiology Sciences, Liver and Digestive Research Center, Research Institute for Health Development, Kurdistan University of Medical Sciences, Sanandaj, Iran

5. Department of Microbiology Sciences, Kurdistan University of Medical Sciences, Sanandaj, Iran

6. Department of Biology, Faculty of Sciences, University of Kurdistan, Sanandaj, Iran

7. Lung Diseases and Allergy Research Center, Kurdistan University of Medical Sciences, Sanandaj, Iran

Corresponding Author:

S.hasani@muk.ac.ir.

Received 09 November 2019 Accepted 10 March 2020 Published 31 March 2020

Production and Hosting by Knowledge E

(C) Hasani. This article is distributed under the terms of the Creative Commons Attribution License, which permits unrestricted use and redistribution provided that the original author and source are credited.

Editor-in-Chief:

Prof. Mohammad A. M. Ibnouf

\section{Abstract}

Introduction: Bacterial resistance to antibacterial agents is a very serious threat to public health. Where some antibacterial agents prove ineffective, the antibacterial properties of honey have been shown to be highly efficacious against several human bacterial pathogens. The purpose of this study is to investigate the sensitivity of Staphylococcus aureus isolated from the nursing staff of a hospital to natural honey. Methods: In this study, 35 strains of methicillin-resistant S. aureus samples were selected from hospital staff's nasal swabs. Two strains were vancomycin-resistant. The serial dilution tube test methodwas used to determine minimum inhibitory concentration (MIC). The susceptibility of each strain of staph bacteria to natural honey without wax was determined and compared with that of a glucose solution with the same density.

Results: In all strains, except for the two strains resistant to vancomycin, MIC level was $<8.3 \%(\mathrm{v} / \mathrm{v})$. The MIC of glucose as dense as honey was four times higher. The two vancomycin-resistant strains were completely resistant to natural honey.

Conclusions: This study has therefore demonstrated that inhibiting bacterial growth is not merely done by purely natural honey not because of osmolality, but vancomycinresistant bacteria are not sensitive to natural honey.

Key words: Sensitivity, Staphylococcus aureus, natural honey, minimum inhibitory concentration 


\section{Introduction}

Increased use of complementary medications has led to a lot of interest in traditional treatments. One treatment that has attracted a lot of interest is honey [1]. Research shows that honey has functional properties in promoting human health, which can be attributed to its osmolarity and antibacterial characteristics [2]. Honey collected from different geographical areas has shown different activities [3], and it has traditionally been used to treat burns, infected and untreated wounds, stomach ulcers, pimples, peptic ulcers, [4], and decrease cough symptoms [5]. It has also been reported that honey has anti-inflammatory, antibacterial, antifungal, and antioxidant effects and is effective against several human bacterial pathogens including Escherichia coli, Salmonella typhimurium, and Staphylococcus aureus [6].

Scientists first reported the ability of honey to eliminate microbial diseases in the late 1800 s, but with the emergence of antibiotics in the early 1900 s, scientists' interest in honey diminished [7]. However, as resistant pathogens developed, the effect of antibiotics reduced. This kind of bacterial resistance to antibacterial agents is a very serious public health threat [8]. The number of newly developed antibiotics is limited when compared with the increase in the preponderance of bacterial resistance, and there is an increasing need for the development of alternative antimicrobial strategies [9]. Therefore, our ability to treat disease effectively depends on the development of new drugs and one potential source of new drugs is traditional medicine [10].

Honey has long been offering a wide range of antibacterial properties [11, 12], although the specific anti-bacterial mechanism is unclear [13] and perhaps hydrogen peroxide, organic acids, Flavonoids, nectar, bee wax, pollen are the important chemical factors for this property. Regardless, it can be considered as an appropriate and safe source of medicinal treatment for humans [14]. Therefore, the aim of this study was to investigate the sensitivity of $S$. aureus to natural honey in samples taken from nursing staff.

\section{Methods}

In this laboratory-controlled study, 35 different types of S. aureus with antibiotic properties were collected. The study investigates the sensitivity of S. aureus to natural honey.

The honey used in this study was obtained from a farm in a mountainous area. Bees produce honey from the dominant plant species. The honey samples used in this investigation were refined and without wax. Sugar was used in the study as control for comparison with honey, in the form of glucose. 
Sample size: 33 species of these bacteria were resistant to methicillin and 2 species were vancomycin-resistant. The details of vancomycin-resistant strains sensitive are as follows:

Antibiotic Susceptibility of Vancomycin-Resistant Strains and Determination of MIC and MBC.

\begin{tabular}{|c|c|c|c|c|c|c|c|c|c|c|c|c|}
\hline 0 & 4 & 8 & 16 & 32 & 64 & 128 & 256 & 512 & 1024 & 2048 & 4098 & $\begin{array}{c}\text { Sample } \\
\text { dilution }\end{array}$ \\
\hline- & - & - & - & - & - & - & - & - & - & - & - & 6 \\
\hline- & - & - & - & - & - & - & - & - & - & - & - & 29 \\
\hline
\end{tabular}

\section{Determining MIC}

In this study, the minimum inhibitory concentration (MIC) of honey was investigated using the test tube serial dilution method [15]. Data were collected through tube medium, adding different concentrations of honey and sugar solutions into the tubes and assessing the bacterial growth. Each sample comprised of three series of 10 tubes. When the concentration was created, a bacteria culture was produced. This allowed us to determine the MIC for bacterial growth in the presence of honey and sugar solution.

The test tube serial dilution method is very accurate and sensitive, but it is not routinely used in clinical laboratories. This procedure is done in two micro tubes, in which the MIC of a certain bacteria can be calculated. Using this method, 10 sterile tubes (dimensions mm $100 \times 13$ ) were numbered and one of the tube was considered as the control group. In each of the tubes from 2 to 10, and control tube, 1cc of MullerHinton broth was poured into a sterilized medium and then a sterilized solution made from honey ( $1 \mathrm{~g}$ per $1 \mathrm{ml}$ ) (sterilized disposable filter with a pore diameter of 0/45 $\mu \mathrm{m}$ ) was added. In tube no 1, $2 \mathrm{ml}$ of culture medium was poured and from tube 1,1 ml was removed and then added to tube 2 to make 5.0 dilutions; similarly serial dilutions were prepared (twice less than the previous tube); $1 \mathrm{ml}$ of solution was removed from the last tube and thrown away. The control tube had no honey inside. All tubes and pipes were then provided with $1 \mathrm{cc}$ of suspension of bacteria (S. aureus). The complex was incubated for $24 \mathrm{hr}$ at $37^{\circ} \mathrm{C}$. After $24 \mathrm{hr}$, the tubes were examined.

\section{Determining MBC}

The MBC (minimum bactericidal concentration) is obtained in relation to the MIC. MBC is usually two to four times as much as MIC. The last tube in which bacteria did not grow was considered as the MIC. Then from the MIC tube and the three tubes before that 
(001/0 ml volume) was removed and cultured (such as blood agar Newest Garya) on a solid medium. After incubation, investigation of MBC's plates was determined including the density of antibiotics with $<99 \%$ growth. As mentioned previously, MBC is usually two to four times of MIC. This method was used to evaluate the MIC and MBC of honey. To compare the effects of honey and glucose, MIC and MBC for glucose were calculated to determine the osmotic effect of honey on the property or its ingredients. In the dilution of glucose as the dilution $\mathrm{g} / \mathrm{ml} 1$ was not possible, therefore, a series of tube No. 3 were prepared.

\section{Data Analysis}

Data were analyzed using the SPSS 18 software and the Chi-square test.

\section{Results}

The staphylococcus species used in this study were all resistant to glucosacchillin; 33 species of these bacteria were resistant to methicillin and 2 to vancomycin (Table 1). Table 2 describes the determination of MIC and MBC of vancomycin-resistant strains in an antibiotic. The MIC for these two species was 0.512 for vancomycin; 35 species were at concentrations of $66 / 7 \%, 33 / 3 \%, 16 / 7 \%, 8 / 3 \%, 4 / 2 \%, 2 / 08 \%, 1 / 04 \%, 0 / 52 \%, 0 / 26 \%$ $(v / v \%)$. Honey tube was cultured in vitro and the results of the development and growth of this species are shown in Table 3. The 35 species at concentrations of $16 / 7 \%, 8 / 3 \%$, $4 / 2 \%, 2 / 08 \%, 1 / 04 \%, 0 / 52 \%, 0 / 26 \%$ of glucose in the culture medium were cultured in tubular environments.

TABLE 1: The Prevalence of Antibiotic of Staphylococcus Aureus Isolated from the Nasal Swabs of Tohid Hospital Staff.

\begin{tabular}{|l|c|c|c|c|c|c|c|c|}
\hline $\begin{array}{l}\text { Antibiotic } \\
\text { results }\end{array}$ & \multicolumn{2}{|c|}{ Resistant } & \multicolumn{2}{c|}{ Semi-sensitive } & \multicolumn{2}{c|}{ Sensitive } & \multicolumn{2}{c|}{ Total } \\
\hline Gercentage & Number & Percentage & Number & Percentage & Number & Percentage & Number \\
\hline Vancomycin & 97 & 65 & 1.5 & 1 & 1.5 & 1 & 67 & 100 \\
\hline Rifampin & 3 & 2 & 0 & 0 & 97 & 65 & 67 & 100 \\
\hline Erythromycin & 4.5 & 3 & 0 & 0 & 95.5 & 64 & 67 & 100 \\
\hline Gentamicin & 4.5 & 3 & 9 & 6 & 86.5 & 58 & 67 & 100 \\
\hline Penicillin & 6 & 4 & 0 & 0 & 94 & 63 & 67 & 100 \\
\hline Ciprofloxacin & 100 & 67 & 0 & 0 & 0 & 0 & 67 & 100 \\
\hline Cefalexin & 1.5 & 1 & 0 & 0 & 98.5 & 66 & 67 & 100 \\
\hline
\end{tabular}


TABLE 2: Antibiotic Susceptibility of Vancomycin-Resistant Strains and Determination of MIC And MBC.

\begin{tabular}{|c|c|c|c|c|c|c|c|c|c|c|c|c|}
\hline 4096 & 2048 & 1024 & 512 & 256 & 128 & 64 & 32 & 16 & 8 & 4 & 0 & $\begin{array}{c}\text { Sample } \\
\text { dilution }\end{array}$ \\
\hline- & - & - & - & - & - & - & - & - & - & - & - & 6 \\
\hline- & - & - & - & - & - & - & - & - & - & - & - & 39 \\
\hline
\end{tabular}

TABLE 3: Growth Rate of 35 Strains of Staphylococcus Aureus in Different Concentrations of Natural Honey in Tubular Culture.

\begin{tabular}{|c|c|c|c|c|}
\hline \multicolumn{2}{|c|}{ No growth } & \multicolumn{3}{|c|}{ Growth } \\
\hline Number & Percentage & Number & Percentage & Result \\
\hline 33 & 94.3 & 2 & 5.7 & 66.7 \\
\hline 31 & 88.5 & 4 & 11.5 & 33.3 \\
\hline 30 & 85.7 & 5 & 14.3 & 16.7 \\
\hline 23 & 65.7 & 12 & 34.3 & 8.3 \\
\hline 0 & 0 & 35 & 100 & 4.2 \\
\hline 0 & 0 & 35 & 100 & 2.08 \\
\hline 0 & 0 & 35 & 100 & 1.04 \\
\hline 0 & 0 & 35 & 100 & 0.52 \\
\hline 0 & 0 & 35 & 100 & 0.26 \\
\hline
\end{tabular}

Except for concentrations of $1,0.5$, and 0.25 , they were grown in all concentrations of glucose. The susceptibility of 35 strains of MIC S. aureus are shown in Table 4. Based on the results, $69 / 7 \%$ of MIC species had $8 / 3 \%$ (v/v\%). Two types of samples of Staphylococcus used in the study previously had antibiotic resistance to vancomycin. They showed full resistance to natural honey and grew at all concentrations. In a study of 33 strains of $S$. aureus which were susceptible to natural honey from the results (Table 4), 17 species of Staphylococcus (51/8\%) had 8.3\% MBC (v/v\%). In comparison of MIC and MBC of Staphylococcus species in a medium containing honey and glucose, a significant difference was seen. MIC and MBC of honey was at least a quarter of glucose (Table 5).

TABLE 4: Frequency of MIC of 33 Species of Honey-Sensitive Staphylococcus aureus.

\begin{tabular}{|c|c|c|}
\hline Number & Percentage & Percentage $(\mathrm{v} / \mathrm{v})$ \\
\hline 2 & 6 & 66.7 \\
\hline 1 & 3.1 & 33.3 \\
\hline 7 & 21.2 & 16.7 \\
\hline 23 & 69.7 & 8.3 \\
\hline 33 & 0 & 4.2 \\
\hline
\end{tabular}


TABLE 5: Frequency of MBC of 33 Species of Honey-Sensitive Staphylococcus aureus.

\begin{tabular}{|c|c|c|}
\hline Number & Percentage & Concentration $(\mathrm{v} / \mathrm{v})$ \\
\hline 3 & 9 & 66.7 \\
\hline 4 & 12 & 33.3 \\
\hline 9 & 27.2 & 16.7 \\
\hline 17 & 51.8 & 8.3 \\
\hline 0 & 0 & 4.2 \\
\hline
\end{tabular}

\section{Discussion}

Based on this study, $94.3 \%$ of the tested strains did not grow in $66.7 \%(\mathrm{v} / \mathrm{v} \%)$ of honey, and the MIC of honey as an antibacterial solution ( $\mathrm{v} / \mathrm{v} \%$ ) was $8.3 \%$. In the Shimaa T. Omara study, honey had antibacterial activity and the MIC (v/v\%) was 5 and 2.5 [16]. In a study by Aamer and colleagues, all tested honey showed antibacterial activity against multi-drug-resistant bacterial strains [17]. Due to the fact that in the concentration of $8.3 \%$ of honey, $94.2 \%$ of the bacteria did not grow, but in the case of glucose, all bacteria have grown in this concentration, and even in the concentration of four times this concentration there has been growth of the bacterium in glucose, this study concludes that the lack of growth of the bacterium in the concentration ( $v / v \%)$ of $8.3 \%$ honey is not related to the effect of the concentration and osmotic properties of honey, because in the same concentration of glucose, despite the presence of osmotic, bacterial growth occurred. Instead, this study demonstrates that the limited bacterium growth is based on the antibacterial properties of honey, which, according to the AF Henriques study, can affect cell division in S. aureus [18]. In the study of R. A. Cooper et al., honey bacterial inhibition was not exclusively related to honey osmolarity [19]. In a study by Mulhouse Vebert, the MIC of honey in the case of Staphylococcus coagulase positive $25 \%(\mathrm{v} / \mathrm{v})$ has been reported [20], which is not consistent with our study. This difference can be due to other honey or honey-producing plant material [21].

In our study, the two strains that had a complete resistance to vancomycin also completely resisted natural honey. However, in the study of Mulan and colleagues, which compared antibiotic susceptible strains with antibiotic-resistant strains, there was no significant difference in the presence of honey [19]. The results of the present study indicate that honey has an antibacterial effect similar to vancomycin, and 33 species of $S$. aureus are susceptible to honey from amongst the 35 species susceptible to 
vancomycin, but the two species resistant to vancomycin are also resistant to honey, which can be used as substituting vancomycin for $S$. aureus and studying it. As noted in the study, honey can be considered as a substitute therapy against specific bacteria [22] and the separation of active ingredient honey is a good way to deal with infection [23].

\section{Recommendations}

Our study shows that honey has antimicrobial effects similar to vancomycin, so honey can be considered as an alternative to vancomycin in Staphylococcus infection and it can also be studied further.

\section{Conflict of Interest}

The authors report no conflict of interest or any source of financial support for the research.

\section{Data Availability}

The data used to support the findings of this study are included within the article.

\section{References}

[1] Lusby PE, Coombes AL, Wilkinson JM (2005). Bactericidal activity of different honeys against pathogenic bacteria. Archives of Medical Research. 36(5): 464-467.

[2] Estevinho L, Pereira AP, Moreira L et al. (2008) Antioxidant and antimicrobial effects of phenolic compounds extracts of Northeast Portugal honey. Food and Chemical Toxicology. 46(12): 3774-3779.

[3] Noori A, Al Ghamdi A, Ansari MJ et al. (2013). Differences in composition of honey samples and their impact on the antimicrobial activities against drug multiresistant bacteria and pathogenic fungi. Archives of Medical Research. 44(4): 307-316.

[4] Yaghoobi R, Kazerouni, A (2013). Evidence for clinical use of honey in wound healing as an anti-bacterial, anti-inflammatory anti-oxidant and anti-viral agent: a review. Jundishapur Journal of Natural Pharmaceutical Products. 8(3): 100.

[5] Oduwole O, Udoh EE, Oyo-Ita A et al. (2018). Honey for acute cough in children. Cochrane Database System Review. 4(3): CD007094. 
[6] Jantakee K, Tragoolpua Y (2015). Activities of different types of Thai honey on pathogenic bacteria causing skin diseases, tyrosinase enzyme and generating free radicals. Biological Research. 48(1): 4.

[7] McLoone P, Warnock M, Fyfe L (2016). Honey: a realistic antimicrobial for disorders of the skin. Journal of Microbiology, Immunology and Infection. 49(2): 161-167.

[8] Mandal MD, Mandal S (2011). Honey: its medicinal property and antibacterial activity. Asian Pacific Journal of Tropical Biomedicine. 1(2): 154-160.

[9] Iqbal MN, Anjum AA, Ali MA et al. (2015). Assessment of microbial load of unpasteurized fruit juices and in vitro antibacterial potential of honey against bacterial isolates. The Open Microbiology Journal. 9: 26-32.

[10] Moussa A, Noureddine D, Abdelmelek M et al. (2012). Antibacterial activity of various honey types of Algeria against pathogenic Gram-negative bacilli: Escherichia coli and Pseudomonas aeruginosa. Asian Pacific Journal of Tropical Disease. 2(3): 211-214.

[11] Cooper R, Halas E, Molan P (2002). The efficacy of honey in inhibiting strains of Pseudomonas aeruginosa from infected burns. The Journal of Burn Care \& Rehabilitation. 23(6): 366-370.

[12] Majtan J (2014). Honey: an immunomodulator in wound healing. Wound Repair and Regeneration. 22(2): 187-192.

[13] Nassar HM, Li M, Gregory RL (2012). Effect of honey on Streptococcus mutans growth and biofilm formation. Applied and Environmental Microbiology. 78(2): 536-540.

[14] Omoya F, Akharaiyi F (2011). Mixture of honey and ginger extract for antibacterial assessment on some clinical isolates. International Journal of Pharmaceutical and Biomedical Research. 2(1): 39-47.

[15] Wasihun AG, Kasa BG (2016). Evaluation of antibacterial activity of honey against multidrug resistant bacteria in Ayder Referral and Teaching Hospital, Northern Ethiopia. SpringerP/us. 5(1): 842.

[16] Omara ST (2017). MIC and MBC of honey and gold nanoparticles against methicillinresistant (MRSA) and vancomycin-resistant (VRSA) coagulase-positive S. aureus isolated from contagious bovine clinical mastitis. Journal of Genetic Engineering and Biotechnology. 15(1): 219-230.

[17] Aamer A, Abdul-Hafeez, M, Sayed S (2014). Minimum inhibitory and bactericidal concentrations (MIC and $\mathrm{MBC}$ ) of honey and bee propolis against multi-drug resistant (MDR) Staphylococcus sp. isolated from bovine clinical mastitis. Alternative \& Integrative Medicine. 3(4): 1-9. 
[18] Henriques A, Jenkins R, Burton $N$ et al. (2010). The intracellular effects of manuka honey on Staphylococcus aureus. European Journal of Clinical Microbiology \& Infectious Diseases. 29(1): 45.

[19] Cooper R, Molan P, Harding K (2002). The sensitivity to honey of Gram $\square$ positive cocci of clinical significance isolated from wounds. Journal of Applied Microbiology. 93(5): 857-863.

[20] Molan P, Brett M eds. (1998). Honey has potential as a dressing for wounds infected with MRSA. The Second Australian Wound Management Association Conference Brisbane, Australia.

[21] Mullai V, Menon T (2007). Bactericidal activity of different types of honey against clinical and environmental isolates of Pseudomonas aeruginosa. The Journal of Alternative and Complementary Medicine. 13(4): 439-442.

[22] Al-Naama RT (2009). Evaluation of in-vitro inhibitory effect of honey on some microbial isolate. African Journal of Bacteriology Research. 1(6): 64-67.

[23] Noori A, Al-Ghamdi A, Ansari MJ et al. (2012). Synergistic effects of honey and propolis toward drug multi-resistant Staphylococcus aureus, Escherichia coli and Candida albicans isolates in single and polymicrobial cultures. International Journal of Medical Sciences. 9(9): 793. 